1. College of Civil Engineering, Shijiazhuang TieDao University,

Shijiazhuang, P.R. China

8

2. Department of Bridge Engineering, College of Civil Engineering, Tongji University,

9

Shanghai, P.R. China

10

11

12

13

14

15

16

17

18

19

20

21

22

23

24 Running headline: Three Dimensional Extension for Park and Ang Damage Model

25

26

27

28

* Corresponding author: Tel.:+86-21-65983116-2805; Fax: +86-21-65976719;

29

E-mail: jjqxu@tongji.edu.cn

(C) 2016. This manuscript version is made available under the Elsevier user license http://www.elsevier.com/open-access/userlicense/1.0/ 
2 Abstract: Proper evaluation for the damage of a structural member lays the basis for the 3 performance-based seismic design procedure. The damage in a reinforced concrete (RC) pier due 4 to an earthquake may be three dimensional, i.e. biaxial bending with varying axial load. However, 5 the existing damage models generally can only be applied to one dimensional cases, i.e. uniaxial 6 bending with constant axial load. To compensate this gap, the traditional widely-used Park and 7 Ang damage model is extended to count cases of three dimensional damages in this paper. The 8 new developed model is based on the moment-rotation relationship. Determination of relevant 9 variables in the proposed model is presented in detail. Two unknown parameters are determined 10 from experimental data through two rounds of traversal search. In addition, a new set of performance levels compatible to this extended Park and Ang model is redefined. The applicability of the damage model under various one-dimensional loading paths and under spatial loadings is verified respectively. The results indicate that the extended Park and Ang damage model together with the parameters and the performance leveling criterion forms an integrated damage assessment index, which can effectively evaluate the three dimensional damage of a RC pier. design 
The performance-based seismic design method makes it possible for designers to control the seismic damage level of structure in a rational range and it generally requires the damage in structural members due to an earthquake attack to be assessed quantitatively. Various damage models for this purpose forwarded by a few researchers over the past decades are available in literature.

One of the earliest and simplest measures for evaluating seismic damage is the ductility-based method (Powell and Allahabadi, 1988), which is generally defined as the ratio of concurrent ductility response to the ductility capacity. Damage models that are based on the deterioration in the property of stiffness have also been widely explored (Roufaiel and Merer, 1987; Banon et al., 1981; Di Pasquale et al. 1990; Kim et al., 2005; Ghobarah et al., 1999).

It is now generally accepted that the damage level of a structural member is not only dependant on the maximum deformation reached but also the number of load cycles and hysteretic energy absorbed (Banon et al., 1980; Colombo and Negro, 2005). Banon et al. (1981) proposed a damage index using a normalized cumulative rotation by extending the ductility-based method to cover repeated cyclic loading. The best known and most widely explored damage index, which consists of a simple linear combination of normalized deformation and hysteric energy absorption, was proposed by Park and Ang (1985) as shown in Eq.(1).

$$
D=\frac{\delta_{m}}{\delta_{u}}+\beta \frac{\int d E}{F_{y} \delta_{u}}
$$

46 where $\delta_{m}=$ maximum deformation; $\delta_{u}=$ ultimate deformation under monotonic loading; $F_{y}=$ yield strength; $d E=$ incremental in absorbed hysteretic energy and $\beta=$ non-negative 
parameter.

49

Park and Ang damage model has later on been improved and modified by a few

50

51

52

53 following

$$
D=\frac{\varphi_{m}-\varphi_{\mathrm{y}}}{\varphi_{u}-\varphi_{\mathrm{y}}}+\beta_{e} \frac{\int d E}{M_{y} \varphi_{u}}
$$

54 where $\varphi_{m}=$ maximum curvature; $\varphi_{u}=$ ultimate curvature under monotonic loading; $M_{y}=$ 55 yield moment; $d E=$ incremental in absorbed hysteretic energy and $\beta_{e}=$ non-negative 56 parameter.

57 Under monotonic deformation, if the maximum deformation capacity $\left(\delta_{m}\right)$ is reached, 58 the value of damage index is supposed to be 1.0, which is an indication of potential failure. 59 However, as is evident from Eq.(1), the Park and Ang damage model result in a value greater 60 than 1.0. To correct this drawback, Chai et al. (1995) modified Park and Ang damage model 61 by accounting the plastic strain energy dissipated by the structure under a monotonic 62 response. It was subtracted form the energy term, which is as following

$$
D=\frac{\delta_{m}}{\delta_{u}}+\beta^{*} \frac{\int d E-E_{h m}}{F_{y} \delta_{u}}
$$

63 Where $E_{h m}$ is plastic strain energy dissipated by the structure under a monotonic loading; and $\beta^{*}$ is strength deterioration parameter calibrated for the modified model.

For elastic response, when the damage index is supposed to be zero, the value of Park and Ang model [see Eq.(1)] or its modifications [see Eq.(2) or Eq.(3)] will be greater than 
damage indices, in which the sum of weight factors of deformation and energy dissipation is 1.0. They are as follows

$$
\begin{gathered}
D_{1}=\left[\left(1-\alpha_{1}\right)(\mu-1) /\left(\mu_{\text {mon }}-1\right)\right]+\alpha_{1}\left(E / E_{\text {mon }}\right) \\
D_{2}=\left[\left(1-\alpha_{2}\right)(\mu-1) /\left(\mu_{\text {mon }}-1\right)\right]+\alpha_{2}\left(E / E_{\text {mon }}\right)^{1 / 2}
\end{gathered}
$$

70

71

Where $\mu=\delta_{\max } / \delta_{y}$ is displacement ductility; $\delta_{y}$ is yield deformation; $\mu=1$ if the response remains elastic $(\mu \leq 1) . \mu_{m o n}$ is monotonic displacement ductility capacity; $E$ is hysteretic energy demanded by earthquake ground motion; $E_{\text {mon }}$ is the hysteretic energy capacity under monotonically increasing lateral deformation; $0 \leq \alpha_{1} \leq 1$ and $0 \leq \alpha_{2} \leq 1$ is constant coefficients.

According to the findings by Kunnath et al. (1997) that with different magnitude of deformation, the same energy dissipation would lead to different damage level, Wang et al.(2004) presented another version of modification for Park and Ang model as shown in Eq. (6).

$$
D=(1-\beta) \frac{\delta_{m}-\delta_{y}}{\delta_{u}-\delta_{y}}+\beta \frac{\sum \beta_{i} E_{i}}{F_{y}\left(\delta_{u}-\delta_{y}\right)}
$$

where $\beta_{i}$ is the energy weight factor related to the loading histories that is used to consider the phenomenon found by Kunnath et al. (1997); the other parameters have the same meaning as those in Eq.(1).

Although much improvement has been made in recent years on Park and Ang damage models, there is a drawback that they generally deal with load cases of combined constant axial load and uniaxial bending. The damage assessment under load cases of combined varying axial force and biaxial bending is seldom studied. Nevertheless, it is more likely that the structural members would subjected to three-dimensional loading under earthquake, i.e. 
the damage could be three-dimension. To rationally assess the damage of a structure member under three-dimensional loads, it is of great value to establish a three-dimensional damage model.

The work carried out herein aims to compensate the above research gap. It proposes a three-dimensional extension of the Park and Ang damage model. The model parameters are fitted using a group of experiments conducted by Mo et al. (2000). Various damage levels are then defined. The applicability of the proposed damage model is then verified based on two sets of tests, one contains six specimens under different loading paths of one-dimensional and another consists of six specimens under spatial force.

\section{Three Dimensional Extension of Park and Ang Damage Model}

Four considerations can be summarized from the improved forms of Park and Ang damage model mentioned above, which are as follows,

1) Recoverable deformation should be subtracted from the deformation, which was raised by Kunnath et al. (1992) [see Eq.(2)].

2) Under monotonic deformation, if the maximum deformation capacity $\left(\delta_{m}\right)$ is reached, the value of damage index is supposed to be 1.0. Therefor the plastic energy dissipated by the structure under a monotonic response should be subtracted form the energy term, which was raised by Chai et al. (1995) [see Eq.(3)].

3) For elastic response, when the damage index is supposed to be zero. Therefor, the sum of weight factors of deformation and energy is 1.0 , which was raised by Bozorgnia and Bertero (2001a, b) [see Eq.(4)-(5)].

4) The same energy dissipation under different magnitude of deformation would lead to different damage level; and the energy weight factor was introduced by Wang et al.(2004) [see Eq. (6)]. 
These improvements should be considered in the modified damage model proposed in this paper. 1) and 4) were directly absorbed, while 2) and 3) were considered together. Rather than the plastic energy dissipated by the structure under a monotonic response, the elastic energy was subtracted from the total energy dissipation in the proposed model; and like improvements in 3), the sum of weight factors of deformation and energy was set to be 1.0. This approaches can both satisfy the requirements in 2) and 3).

Based on the Park and Ang damage model, and with the above improvements considered, a three-dimensional damage index in terms of moment and rotation is proposed as follows:

$$
D=(1-\beta) \bar{\mu}_{\theta, \max }+\beta \int \alpha_{\max } \frac{d E_{p}}{E_{\text {mon }}}
$$

where $\beta$ is the combination factor or weight factor of energy dissipation; $\bar{\mu}_{\theta \text {,max }}$ is the maximum normalized rotation ductility factor; $d E_{p}$ is the increment of plastic energy dissipation; $E_{\text {mon }}$ is the plastic energy dissipation under monotonic loading when a structural member completely collapses, and $\alpha_{\max }$ is the energy dissipation correction term. In Eq.(7), the first and second parts evaluate the damage due to deformation and energy dissipation respectively. Determination of relevant variables in Eq.(7) will be presented in detail.

\subsection{The Maximum Normalized Rotation Ductility Factor}

the deformation term of the modified model in Eq.(7) needs consider the biaxial deformation. The extension of the maximum normalized rotation ductility factor $\bar{\mu}_{\theta \text {, max }}$ can be calculated as: 


$$
\begin{gathered}
\bar{\mu}_{\theta, \max }=\max _{i=0}^{i=\text { current step }}\left\{\bar{\mu}_{\theta}\left(\theta_{i}\right)\right\} \\
\bar{\mu}_{\theta}\left(\theta_{i}\right)=\frac{\theta_{i}-\theta_{y, i}}{\theta_{u, i}-\theta_{y, i}} \\
\theta_{i}=\left\|\left(\theta_{2 i}, \theta_{3 i}\right)\right\|
\end{gathered}
$$

130 where $\bar{\mu}_{\theta}\left(\theta_{i}\right)$ is the normalized rotation ductility factor at the i-th time step. $\theta_{i}$ is the 131 rotation of the plastic hinge area. It should be noted that under three-dimensional loading, $\theta_{i}$ 132 denotes the modulus of rotation vector $\left(\theta_{2, i}, \theta_{3, i}\right)$ in the two principal axes and is positive as 133 shown in Eq.(10). $\theta_{2, i}, \theta_{3, i}$ are rotations along principal axes 2 and 3 respectively, where 123 134 denotes the element's local coordinate system. For uniaxial bending cases, then $\theta_{i}=\left|\theta_{2, i}\right|$ or 135 $\theta_{i}=\left|\theta_{3, i}\right| . \quad \theta_{y, i}$ and $\theta_{u, i}$ is the yield rotation and ultimate rotation in the direction of 136 response vector $\left(\theta_{2, i}, \theta_{3, i}\right)$ corresponding to the axial load level in the plastic hinge area in 137 the current time step. Both $\theta_{y, i}$ and $\theta_{u, i}$ are positive.

138 In the damage models shown in Eqs. (1) to (6), the damage level caused by excessive 139 deformation is related to constant properties of the member, i.e. yield and ultimate 140 deformation which are fixed values during the computational process. For the improved 141 damage model proposed herein, the damage of deformation could be calculated in every time 142 step respectively to involve the changes of bending direction and axial force. The "normalized ductility" is used to express damage of deformation, since there is no damage in 144 the elastic state.

2.2 The Plastic Energy Dissipation Increment $d E_{p}$ 
147 (2) to (6), the energy terms are calculated by the half cycle, of which the starting or ending 148 point is usually the zero response (force or moment) point. However, for three-dimensional 149 loading, moments and forces could always be non-zero values, thus there isn't the concept of 150 half cycle, as illustrated in Fig.1 of a cantilever column under biaxial displacement loading. 151 The biaxial loading path is $0 \rightarrow a \rightarrow b \rightarrow \ldots \rightarrow k$. In Fig.1, the vertical displacement or the horizontal displacement is non-zero at any point. Consequently, the force or moment may be non-zero at any time.

Since the elastic energy dissipation $E_{e}$ is reversible, or only slight damage would be caused by the elastic energy. It is therefore only plastic energy dissipation increment is considered in the proposed damage model, and the value of damage index $D$ is zero before any plastic response occurs.

Fig. 2 shows the moment-rotation relationship for the uniaxial loading along principal axes 2. In Fig.2(a), the loading path is $O \rightarrow a \rightarrow b$, when unloading takes place at point $\mathrm{b}$, the path follows $\mathrm{b} \rightarrow c$. This paper adopts the assumption which was used by original Clough model that the unloading stiffness is the same with the linear loading stiffness $k_{M_{2}}^{e}$. 

divided into elastic term $E_{2 e}$ and plastic term $E_{2 p}$, as shown by Eq. (15).

$$
\begin{gathered}
\theta_{2}=\theta_{2 e}+\theta_{2 p} \\
\theta_{2 e}=\frac{M_{2}}{k_{M_{2}}^{e}} \\
E_{2 e}=\frac{1}{2} M_{2} \theta_{2 e}=\frac{M_{2}^{2}}{2 k_{M_{2}}^{e}} \\
E_{2}=\int M_{2} d \theta_{2} \\
E_{2 p}=E_{2}-E_{2 e}
\end{gathered}
$$
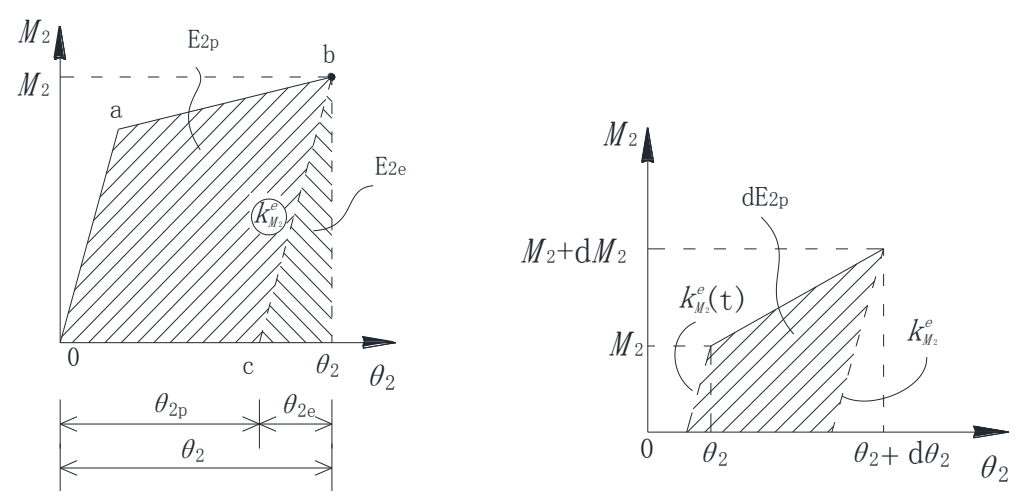

(b) Schematic diagram of $d E_{e}$ and $d E_{p}$

Fig.2 Schematic diagram of energy dissipation for the uniaxial loading along principal axes 2

In Fig.2(b), the increment of rotation $\theta_{2}$ is denoted by $d \theta_{2}$. The total energy 
dissipation increment $d E_{2}$ can be calculated according to Eq. (16), and the elastic energy dissipation increment $d E_{2 e}$ can be calculated by Eq.(17). According to Eq. (15), the plastic energy dissipation increment $d E_{p}$ can be calculated by Eq.(18).

$$
\begin{gathered}
d E_{2}=\int_{\theta_{2}}^{\theta_{2}+d \theta_{2}} M_{2} d \theta_{2}=\left(M_{2}+\frac{d M_{2}}{2}\right) d \theta_{2} \\
d E_{2 e}=\frac{\left(M_{2}+d M_{2}\right)^{2}}{2 k_{M_{2}}^{e}}-\frac{M_{2}^{2}}{2 k_{M_{2}}^{e}}=\frac{\left(2 M_{2}+d M_{2}\right) d M_{2}}{2 k_{M_{2}}^{e}} \\
d E_{2 p}=d E_{2}-d E_{2 e}=\left(M_{2}+\frac{d M_{2}}{2}\right) d \theta_{2}-\frac{\left(2 M_{2}+d M_{2}\right) d M_{2}}{2 k_{M_{2}}^{e}}=\frac{\left(2 M_{2}+d M_{2}\right)\left(k_{M_{2}}^{e} d \theta_{2}-d M_{2}\right)}{2 k_{M_{2}}^{e}}
\end{gathered}
$$

Eq. (16)- (18) gives the energy calculation formulas for uniaxial loading pattern. In $3 \mathrm{~d}$ deformation, total energy dissipation increment in plastic-hinge zone of a member under biaxial bending was given by Eq.(19):

$$
\begin{aligned}
& d E=(\mathrm{v} \\
&\left.M+\frac{d \stackrel{\mathrm{v}}{\mathrm{V}}}{2}\right) \mathrm{g} d \mathrm{~V}=\left(M_{2}+\frac{d M_{2}}{2}, M_{3}+\frac{d M_{3}}{2}\right) \mathrm{g}\left(d \theta_{2}, d \theta_{3}\right) \\
&=\left(M_{2}+\frac{d M_{2}}{2}\right) \mathrm{g} d \theta_{2}+\left(M_{3}+\frac{d M_{3}}{2}\right) \mathrm{g} d \theta_{3} \\
&=d E_{2}+d E_{3}
\end{aligned}
$$

In Eq.(19), $M_{3}$ is moment along principal axes 3 of the cross section of structural member, below.

Elastic energy dissipation increment is shown by Eq.(20): 


$$
\begin{aligned}
& d E_{e}=(\mathrm{v} \\
&\left.M+\frac{d \stackrel{v}{M}}{2}\right) \mathrm{g} d \hat{\theta}_{e}=\left(M_{2}+\frac{d M_{2}}{2}, M_{3}+\frac{d M_{3}}{2}\right) \mathrm{g}\left(d \theta_{2 e}, d \theta_{3 e}\right) \\
&=\left(M_{2}+\frac{d M_{2}}{2}\right) \mathrm{g} d \theta_{2 e}+\left(M_{3}+\frac{d M_{3}}{2}\right) \mathrm{g} d \theta_{3 e} \\
&=d E_{2 e}+d E_{3 e}
\end{aligned}
$$

$$
\begin{aligned}
d E_{p}=d E-d E_{e} & =\left(M_{2}+\frac{d M_{2}}{2}\right) \mathrm{g} d \theta_{2}-\left(M_{2}+\frac{d M_{2}}{2}\right) \mathrm{g} d \theta_{2 e}+\left(M_{3}+\frac{d M_{3}}{2}\right) \mathrm{g} d \theta_{3}-\left(M_{3}+\frac{d M_{3}}{2}\right) \mathrm{g} d t \\
& =\frac{\left(2 M_{2}+d M_{2}\right)\left(k_{M_{2}}^{e} d \theta_{2}-d M_{2}\right)}{2 k_{M_{2}}^{e}}+\frac{\left(2 M_{3}+d M_{3}\right)\left(k_{M_{3}}^{e} d \theta_{3}-d M_{3}\right)}{2 k_{M_{3}}^{e}} \\
& =\left(d E_{2}-d E_{2 e}\right)+\left(d E_{3}-d E_{3 e}\right)=d E_{2 p}+d E_{3 p}
\end{aligned}
$$
bending is the superposition of two principal axis. can be ignored. Thus the ideal elastic-plastic relationship of moment-rotation was adopted in this paper. Actually, stiffness hardening could be involved in this damage model, and its form would become slightly complex. The plastic energy dissipation under monotonic loading at failure is shown schematically in Fig. 3. For elastic-perfectly plastic case, the dissipation can be calculated by Eq.(22).

$$
E_{m o n}=M_{y, i}\left(\theta_{u, i}-\theta_{y, i}\right)
$$

where $M_{y, i}$ denotes yield moment at the i-th time step. $M_{y, i}, \theta_{y, i}$ and $\theta_{u, i}$ are properties 
corresponding to the axial load and bending direction at the calculating time. They are all positive.
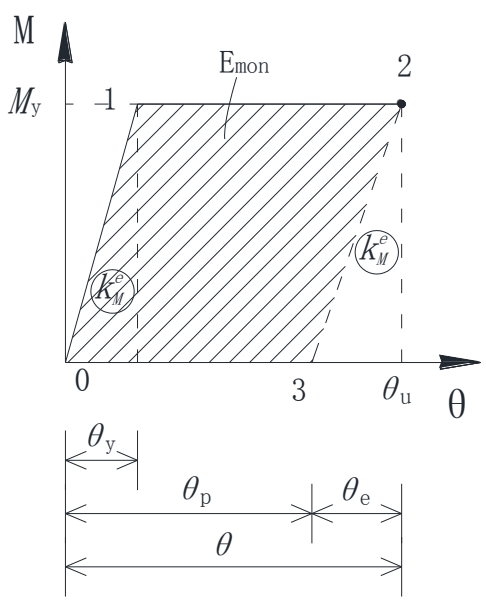

Fig. 3 Plastic energy dissipation $E_{\text {mon }}$ under monotonic loading at failure

In Park and Ang model shown by Eq. (1) and its modified versions shown by Eqs. (2) and (6), the energy terms are all compared to the total or plastic energy dissipation in the monotonic loading till failure. The monotonic energy dissipation $E_{\text {mon }}$ is constant all through the calculation. However, within the consideration of varying axial force and biaxial bending, $E_{m o n}$ changes over time and is time-dependent as show in Eq.(22).

\subsection{Energy Dissipation Correction Term $\alpha_{\max }$}

Experiments have shown that for the same energy dissipation under different deformation magnitude would result in different damage (Kunnath et al., 1997). The modified Park and Ang model by Wang et al. (2004) introduces a dissipation correction coefficient. Actually, Park and Ang(1985) have involved energy dissipation correction term in another damage index with the expression of $\left(\delta / \delta_{u}\right)^{\alpha}$, where $\delta$ is current deformation, $\delta_{u}$ is ultimate deformation under monotonic loading, $\alpha$ is exponential parameter. The energy dissipation correction term is also considered in the there-dimensional damage model, 
and two improvements were involved, (1)the maximum deformation magnitude all through

216

the time history, not only deformation magnitude at the current time step, is considered in energy dissipation correction term; (2) the elastic deformation is removed, i.e. energy dissipation correction term is 0 while only elastic deformation happened. These two improvement are consistent with the test results conducted by Kunnath et al. (1997). The correction term is calculated as follows:

$$
\begin{aligned}
& \alpha_{\max }=\max _{i=0}^{i=\text { current step }}\left\{\alpha\left(\theta_{i}\right)\right\} \\
& \alpha\left(\theta_{i}\right)= \begin{cases}\beta_{2}\left(\frac{\theta_{i}-\theta_{y, i}}{\theta_{u, i}-\theta_{y, i}}\right)^{\beta_{1}}, & , \theta_{i}>\theta_{y, i} \\
0 & , \theta_{i} \leq \theta_{y, i}\end{cases}
\end{aligned}
$$

In Eqs. (23) and (24), $\beta_{1} \in[0,+\infty)$ is the index for energy dissipation correction, which is constant; $\beta_{2} \in[0,+\infty)$ is also constant. $\alpha\left(\theta_{i}\right)$ is dissipation correction coefficient at the i-th time step. $\theta_{i}, \theta_{y, i}$ and $\theta_{u, i}$ have the same meaning as those in Eq. (9).

So far, there are three undetermined coefficients $\beta, \beta_{1}$ and $\beta_{2}$ in the proposed model of Eqs. (7) and (8).

\subsection{Advantages}

As shown above, three dimensional extensions for Park and Ang damage model has been presented in detail, its characteristics can be summarized as follows,

1) The proposed damage model is based on both deformation and accumulative energy dissipation.

2) The model solves the divergence problem of the upper and lower bound in Park and Ang damage model, that is: a) in elastic deformation, the damage index equals to 0 ; and b) the damage index reaches 1 at member failure. 
3) The deformation weight of energy dissipation is taken into account.

4) Varying axial force and bi-directional bending can be considered.

5) The damage index is monotonically non-decreasing. This meets the demand of irreversibility of damages to RC members.

\section{Correlation between Parameters}

For a damage model, there are two requirements, which are as follows.

(1) Monotonically non-decreasing. The irreversibility of damages to RC members requires the damage model to be non-decreasing.

(2) Excellent predictive capacity. A full damage model contains two parts of contents, the determination of coefficients in the damage formula and the determination of limit values for various damage levels. Both of them are important for the predictive capacity and description ability of damage model.

The proposed model is monotonically non-decreasing in assessing damage level. It can also be seen that in elastic range, calculated damage value $\mathrm{D}$ is 0 . To meet the second requirement, before the limit values of various performance levels are defined, the damage indicating value at complete failure shall be determined. The entire definition of performance levels will be given in section 5 .

Park and Ang (1987) defined the limit value of performance state for their damage model, when $\mathrm{D} \geq 1$, the structure collapses. In the modified Park and Ang models, such as Kunnath et al. (1992) and Wang et al.(2004), when the member fails under monotonically increasing loads, the damage Index D is equal to 1. For most existing improved damage models, the damage index is generally 0 for an undamaged member and 1 for a collapsed member (Williams et al., 1995). The model proposed herein also adopts the strategy. By this requirement, under constant axial loads, members would gain damage value $D=1$ when monotonically increasing load till collapse. In this case, Eq. (8) becomes: 


$$
\bar{\mu}_{\theta, \max }=1
$$

259 Substituting the above equation into Eq. (7), we get

$$
1=(1-\beta)+\beta \int \alpha_{\max } \frac{d E_{p}}{E_{\text {mon }}}
$$

260 that is:

$$
\int \alpha_{\max } \frac{d E_{p}}{E_{m o n}}=1
$$

261 By substituting the energy dissipation correction term $\alpha_{\max }$, plastic energy dissipation

262 increment $d E_{p}$ and plastic energy dissipation $E_{m o n}$ in monotonic load at failure into Eq. (27),

263 we get:

$$
\int_{\theta_{y}}^{\theta_{u}} \beta_{2}\left(\frac{\theta_{i}-\theta_{y}}{\theta_{u}-\theta_{y}}\right)^{\beta_{1}} \frac{(2 M+d M)\left(k_{M}^{e} d \theta-d M\right)}{2 k_{M}^{e}}=1
$$

264 In Eq.(28), when $\theta \in\left(\theta_{y}, \theta_{u}\right), M=M_{y}, d M=0$ and we get:

$$
\beta_{2} \int_{\theta_{y}}^{\theta_{u}}\left(\frac{\theta-\theta_{y}}{\theta_{u}-\theta_{y}}\right)^{\beta_{1}} \frac{d \theta}{\theta_{u}-\theta_{y}}=1
$$

265 According to Eq.(9), we have

$$
\theta=\theta_{y}+\bar{\mu}_{\theta}\left(\theta_{u}-\theta_{y}\right)
$$

And Eq. (29) can be written as

$$
\beta_{2} \int_{0}^{1}\left(\bar{\mu}_{\theta}\right)^{\beta_{1}} d \bar{\mu}_{\theta}=1
$$

266 Integrating of Eq.(31), we get:

$$
\beta_{2}=1+\beta_{1}
$$

267 According to Eq.(32), it can be seen that $\beta_{1}, \beta_{2}$ are related to each other. Eq.(32) is a 
necessary condition of the proposed damage model for the demand of prediction ability when structure members resist monotonically loading, even though the load based by the derivation above is just one of various loading paths.

Therefore, there are only two independent parameters that need to be inferred from experiments, i.e. $\beta$ and $\beta_{1}$.

\section{Parameter Fitting}

Mo et al. (2000) reported the quasi-static experiment results of RC columns. Nine columns with clear height $1650 \mathrm{~mm}$ were tested, all of which failed in bending. The horizontal force is applied at a distance from the top of column by $250 \mathrm{~mm}$. As mentioned by Mo et al. (2000), the plastic hinge length was assigned to $450 \mathrm{~mm}$. The cross section is $400 \mathrm{~mm} \times$ $400 \mathrm{~mm}$, and the thickness of cover is $34 \mathrm{~mm}$.

The determination of $\beta$ and $\beta_{1}$ is performed through two rounds of traversal search, and they are determined in the first and second round respectively. Table I shows the proposed searching range of two searching rounds.

IDARC (Kunnath et al, 1992) requires a user-defined value of $\beta_{e}$ [see Eq.(2)], with a default value of 0.1 and a recommendation that it should not normally exceed 0.5 . Bozorgnia and Bertero (2003) estimated the coefficients $\alpha_{1}$ and $\alpha_{2}$ in Eq.(4) and Eq.(5) by a comparison between the damage index in Eq.(4) and Eq.(5) and the Park and Ang damage model in Eq.(1). The estimated values for $\alpha_{1}$ and $\alpha_{2}$ is from 0.206 to 0.385 . If the weight factor $\beta$ [see Eq.(7)] took very small value, the energy term would made a negligible contribution to the overall index, which therefor took virtually no account of the load cycling effect (Williams et al., 1995). In this paper, the coefficient of $\beta$ is set to be not smaller than 0.1. Based on the above consideration and by comparing with the value of coefficient in 

$[0.2,5]$, which contain the meaningful value range. All "points" in the range by a certain kind of interval are checked to find the best values of $\beta$ and $\beta_{1}$.

Table I Parameter Values for Traversal search

\begin{tabular}{c|ccc|ccc}
\hline Sequence & \multicolumn{3}{|c|}{ The First Search Round } & \multicolumn{3}{c}{ The Second Search Round } \\
\hline Parameter & Min Value & Max Value & Step Size & Min Value & Max Value & Step Size \\
\hline$\beta$ & 0.1 & 0.6 & 0.1 & 0.1 & 0.1 & 0 \\
$\beta_{1}$ & 0.2 & 5 & 0.2 & 0.1 & 5.0 & 0.1 \\
\hline
\end{tabular}

To evaluate the performance of a combination of $\beta$ and $\beta_{1}$, the following damage 296 evaluation function is adopted:

$$
\delta=\sqrt{\frac{\sum_{i=1}^{n}\left(D_{i}-1\right)^{2}}{n}}
$$

297 where $\delta$ is the deviation of damage; $D_{i}$ is the damage value of the $\mathrm{i}$-th specimen 298 corresponding to one set of $\beta$ and $\beta_{1}$; and $n$ is the total amount of experiments. $\delta$ 299 indicates the total deviation of damages of all specimens at failure, and $\mathrm{D}=1$ is supposed to be 300 ideal result.

301 In the first searching round, the relationship of damage deviation $\delta$ and $\beta_{1}$ for given 302 value of $\beta$ is shown in Fig.4(a). From Fig.4(a), it can be seen that when $\beta=0.1$, the 303 damage deviation $\delta$ is smallest in general. Therefore, 0.1 is adopted for $\beta$, which also coincides with the value proposed by Wang et al. (2004) and IDARC(Kunnath et al.,1992). 
305

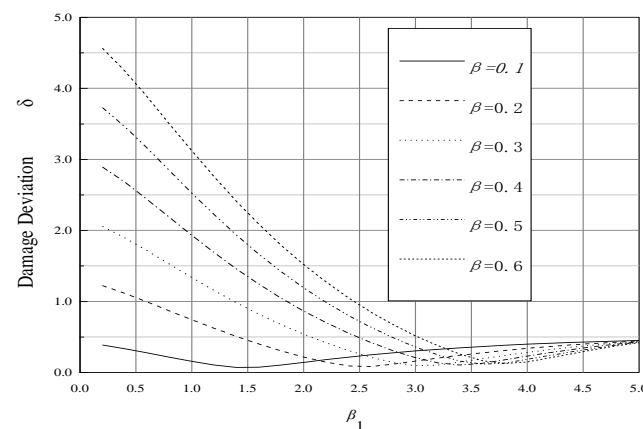

(a) in the first round of search

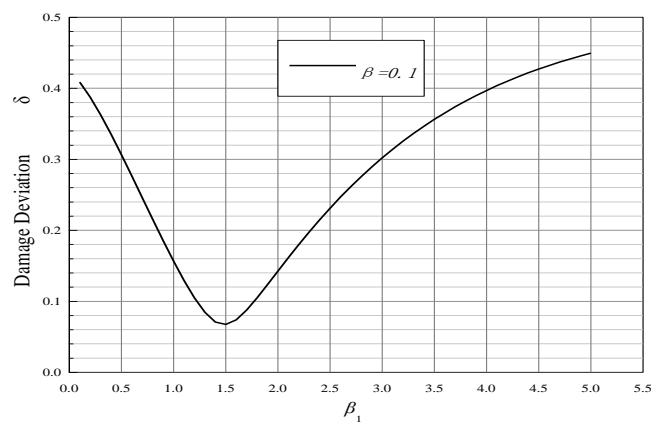

(b)in the second round of search

Fig.4 Relationship between $\beta_{1}$ and damage deviation $\delta$

In the second searching round, taking $\beta=0.1$ and searching range $[0.1,5.0]$ for $\beta_{1}$

with step 0.1, the relationship between damage deviation $\delta$ and $\beta_{1}$ is shown in Fig.4(b).

It can be seen in Fig.4(b) that when $\beta_{1}=1.5$, the deviation parameter $\delta$ has the minimum value. Hence, the parameters are taken as $\beta=0.1$ and $\beta_{1}=1.5$ respectively.

According to Eq.(32),

$$
\beta_{2}=1+\beta_{1}=1+1.5=2.5
$$

Based on the above determined parameters, the damage of the nine specimens in Mo's experiments is shown in Fig.5. The damage values at failure are between 0.903 and 1.124. They are close to 1.00 and can meet engineering accuracy requirements.

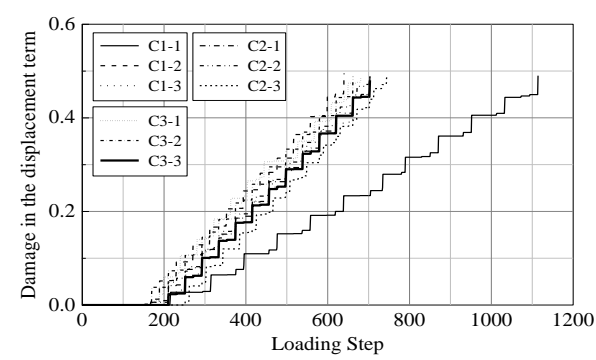

(a)Damage in the displacement term

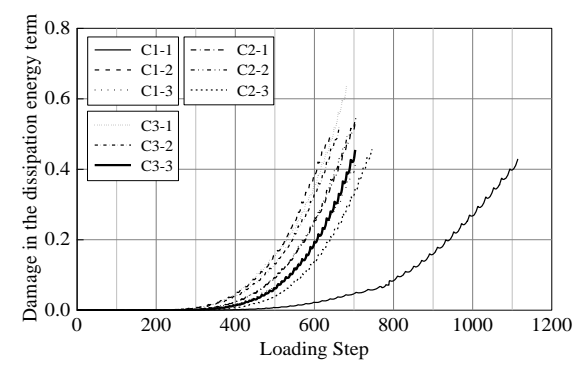

(b)Damage in the dissipation energy term 


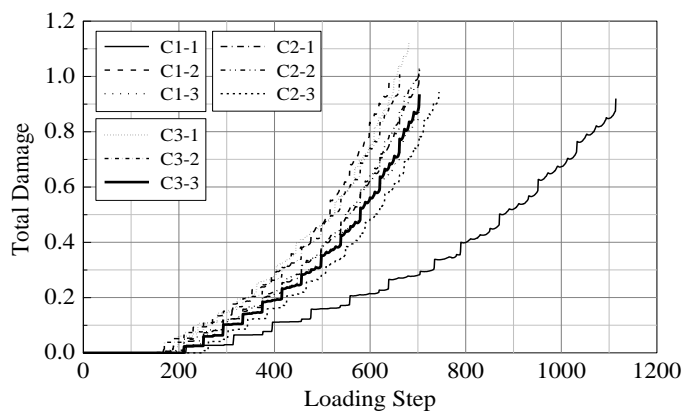

(c)Total damage

Fig.5 The damage of specimens in Mo's experiments(Mo Y L,2000)

Because mechanical properties of reinforced concrete members have great dispersion,

and their bending and damage characteristics are related to reinforcement ratio, stirrup ratio,

shear span ratio, axial compression ratio and so on, $\beta$ and $\beta_{1}$ are related to and are the future.

\section{Definition of Damage States}

The performance-based seismic design of RC structures allows a certain degree of damage. Thus, it is important to precisely determine the damage state for a member, and this is also an integrated part of a damage index as mentioned in section 3.

There are various definitions or standards up to date. Park et al.(1985)suggested the damage indicating value between repairable and irreparable states can be taken as $\mathrm{D}=0.4$. Later on, more refined correlation with damage states are proposed in their subsequent studies(Park et al., 1987) as follows:

Damage value D: $\quad$ State description:

$\mathrm{D}<0.1$

$0.1 \leqslant \mathrm{D}<0.25$

$0.25 \leqslant \mathrm{D}<0.4$

$0.4 \leqslant \mathrm{D}<1.0$
No damage or small local cracks

Slight damage, small cracks

Medium damage, distinct cracks, concrete locally peeling off Severe damage, concrete crushes, and steels expose 

D> 1.0
Collapse

According to the modified Park and Ang damge model proposed by Kunnath et al. (1992), Stone and Taylor (1993) proposed another damage level standard based on experimental results of 82 bridge columns with circular section, which is as follows:

Damage value D: $\quad$ State description:

$\mathrm{D}<0.11 \quad$ No damage or small local cracks

$0.11 \leqslant \mathrm{D}<0.4 \quad$ Repairable

$0.4 \leqslant \mathrm{D}<0.77 \quad$ Irreparable

D $>0.77 \quad$ Collapse

Comparing the two definitions of damage levels described above, one can find that the first one by Park et al. (1987) directly relates the damage degree with material damage process; instead, the second (Stone and Taylor, 1993) define the levels according to post disaster restoration. The first one has clear physical meaning while the second can be directly used in performance evaluation and economic loss assessment and is more convenient for application in performance-based design. So, the second dividing method by Stone and Taylor (1993) was adopted to define the damage level in this paper.

In this section, both the values of the modified Park and Ang index by Kunnath et al. (1992) [see Eq. (2)] and this paper's index have been calculated. It should be noted that because there is difficulty in determination of the combination coefficient $\beta_{e}$ in modified Park and Ang model by Kunnath et al. (1992) [see Eq. (2)], we did not calculate $\beta_{e}$ from formulas, rather we inferred $\beta_{e}$ from Eq. (2), with the assumption that member damage value reaches 1.0 when member fails, which was shown in Eq. (35):

$$
\beta_{e}=\left(1-\frac{\varphi_{m}-\varphi_{\mathrm{y}}}{\varphi_{u}-\varphi_{\mathrm{y}}}\right) / \frac{\int d E}{M_{y} \varphi_{u}}
$$

Based on Eq. (35), values of damage index modified by Kunnath et al. (1992) [see Eq. (2)] were calculated for all specimens. The values corresponding to damage states proposed 
by Stone and Taylor's (1993) were shown in the first line of Error! Not a valid bookmark self-reference., and the corresponding loading time points were recorded. Meanwhile, values of damage index proposed in this paper [see Eq. (7)] at the same loading time points were calculated. They were shown in the second and to the tenth lines of Error! Not a valid bookmark self-reference. The algebraic mean of the damage values from Line 2 to Line 10 were shown in the last line of Error! Not a valid bookmark self-reference..

Table II Damage level limits proposed in this paper

\begin{tabular}{lllllllllllll}
\hline $\begin{array}{l}\text { Value of damage index modified by } \\
\text { Kunnath et al. (1992) [see Eq. }\end{array}$ & \multicolumn{9}{c}{ Value of damage index proposed in this paper [see Eq. (7)] } \\
$\begin{array}{l}\text { (2)] } \\
\text { C1-1 }\end{array}$ & C1-2 & C1-3 & C2-1 & C2-2 & C2-3 & C3-1 & C3-2 & C3-3 & $\begin{array}{c}\text { Average } \\
\text { value }\end{array}$ \\
\hline 0.11 & 0.073 & 0.075 & 0.067 & 0.077 & 0.081 & 0.076 & 0.084 & 0.075 & 0.068 & 0.075 \\
0.40 & 0.280 & 0.293 & 0.276 & 0.297 & 0.307 & 0.291 & 0.328 & 0.295 & 0.291 & 0.295 \\
0.77 & 0.633 & 0.677 & 0.626 & 0.696 & 0.706 & 0.652 & 0.763 & 0.682 & 0.647 & 0.676 \\
1.00 & 0.920 & 0.998 & 0.903 & 1.025 & 1.037 & 0.944 & 1.124 & 1.008 & 0.935 & 0.988 \\
\hline
\end{tabular}

Corresponding to the damage states proposed by Stone and Taylor and referring to the average values of damage index proposed in this paper [see Eq. (7)], which is shown in Based on Eq. (35), values of damage index modified by Kunnath et al. (1992) [see Eq. (2)] were calculated for all specimens. The values corresponding to damage states proposed by Stone and Taylor's (1993) were shown in the first line of Error! Not a valid bookmark self-reference., and the corresponding loading time points were recorded. Meanwhile, values of damage index proposed in this paper [see Eq. (7)] at the same loading time points were calculated. They were shown in the second and to the tenth lines of Error! Not a valid bookmark self-reference. The algebraic mean of the damage values from Line 2 to Line 10 were shown in the last line of Error! Not a valid bookmark self-reference..

Table II, this paper's damage levels and the corresponding state is shown below:

Damage value D:

$$
\begin{aligned}
& 0.00 \leqslant \mathrm{D}<0.08(\approx 0.075) \\
& 0.08 \leqslant \mathrm{D}<0.30(\approx 0.295)
\end{aligned}
$$

State description:

No damage or small local cracks

Can be restored after retrofit 


$$
\begin{array}{ll}
0.30 \leqslant \mathrm{D}<0.68(\approx 0.676) & \text { Should replace structural members } \\
0.68 \leqslant \mathrm{D}<1.00(\approx 0.988) & \text { Collapse }
\end{array}
$$

In the damage levels above, the upper limit value is 1.0, which is the result from regression analysis of damage corresponding to cyclic loading and unloading experiments, and also a starting point of the proposed damage model in Eq.(7) as mentioned in section 2. When the members' dynamic damage in earthquake was predicted, the damage value may be smaller than 1.0 due to loading, unloading path and cycling number. According to the damage limit stages proposed above, when the value of damage index is greater than 0.68 , the member is seriously damaged, and is considered to be failure.

\section{Illustration of the Proposed Damage Model}

\subsection{Experimental Verification of Different One-Dimensional Loading Paths}

The applicability of the proposed model for specimens under different one-dimensional load paths is verified using the experiments (indexed by TP001 TP006) by Takemura and Kawashima(1997). In their experiments, six specimens with the same dimension and rebar configuration were subjected to different loading paths. The specimens are RC cantilever columns, the cross sectional size is $400 \mathrm{~mm} \times 400 \mathrm{~mm}$, the cross section effective length is $\mathrm{h}_{0}=360 \mathrm{~mm}$, the distance between loading point and top of the foundation beam is $L=$ $1245 \mathrm{~mm}$. Convert the force-deformation relationships to moment-rotation, the results are shown in Fig.6, from which we can find that the loading paths are significantly different from each other. 


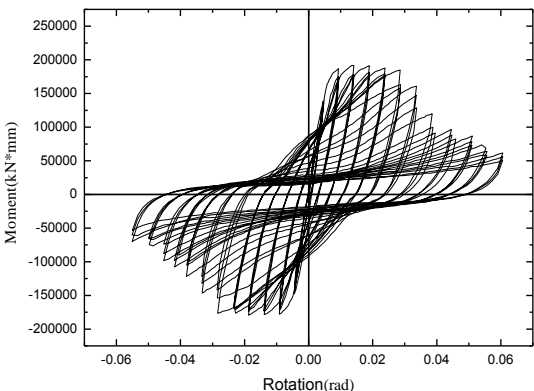

(a) TP001

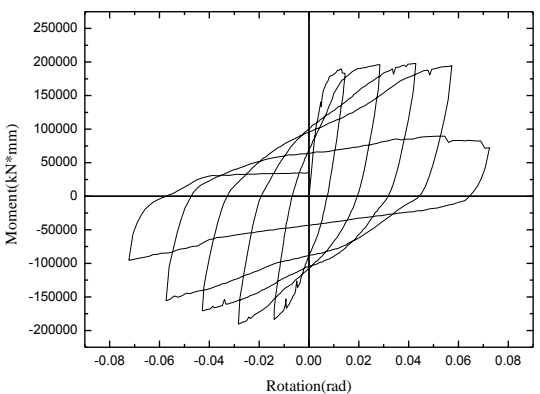

(c) TP003

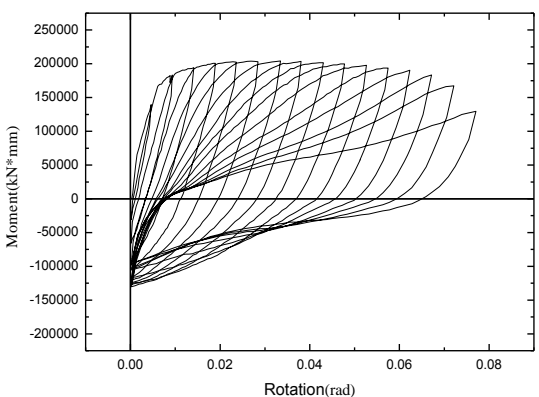

(e) TP005

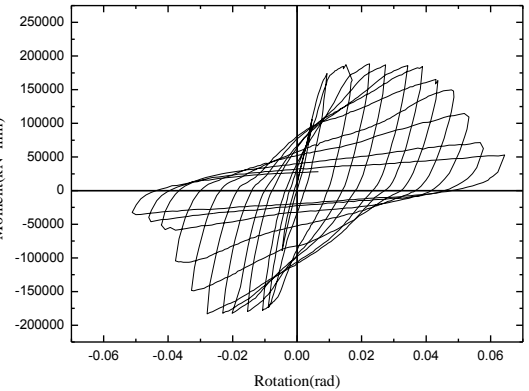

(b) TP002

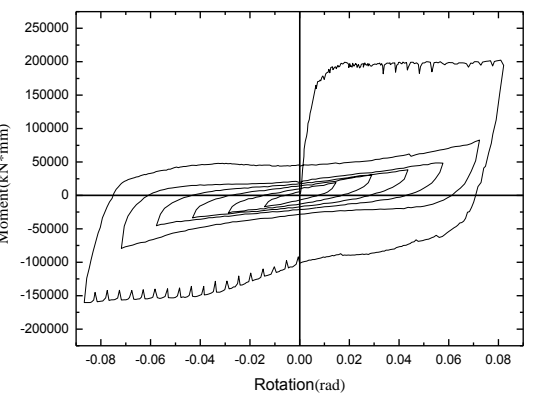

(d) TP004

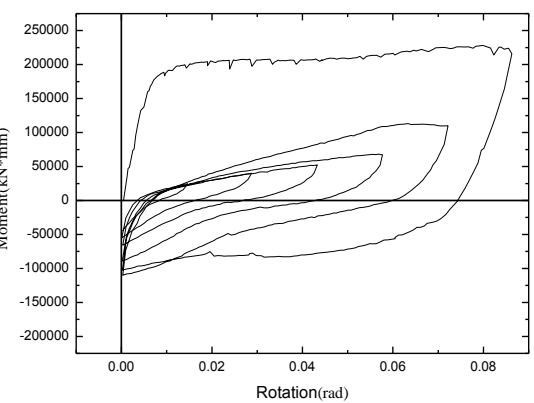

(f) TP006 in Fig.7.

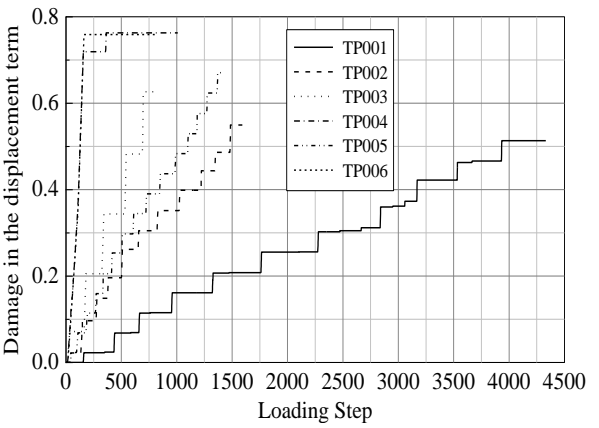
Loading Step

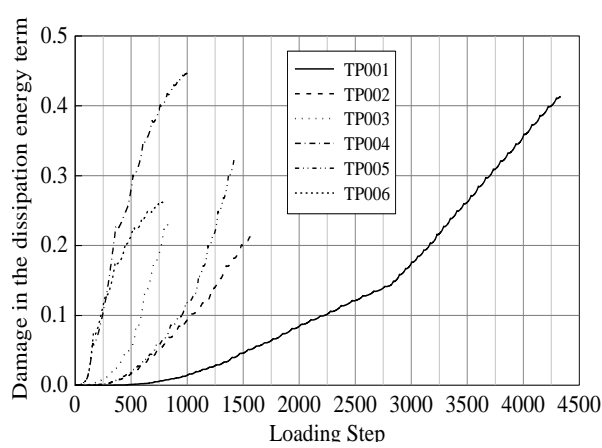

Loading Step 


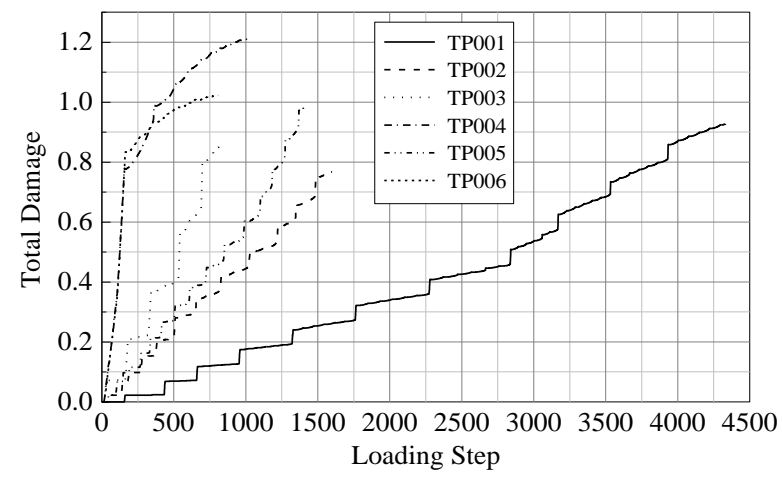

(c)Total damage

Fig.7 The damage of Specimens TP001 TP006

When the loading terminates, the member damage states are shown in Table III.

Table III Damage state of Specimens TP001 TP006 when loading terminates

\begin{tabular}{ccccccc}
\hline Specimens & TP001 & TP002 & TP003 & TP004 & TP005 & TP006 \\
\hline Displacement damage term & 0.51 & 0.55 & 0.63 & 0.76 & 0.67 & 0.76 \\
Dissipative energy damage term & 0.41 & 0.22 & 0.23 & 0.45 & 0.32 & 0.26 \\
Total Damage value & 0.93 & 0.77 & 0.86 & 1.21 & 0.99 & 1.02 \\
Structural State & Collapse & Collapse & Collapse & Collapse & Collapse & Collapse \\
\hline
\end{tabular}

According to the performance limit value, the termination state for each specimen is "collapse". This illustrates that the proposed model is applicable to the damages of specimen with varying loading paths.

6.2 Verification of Spatial Loading Paths

The Kawashima Earthquake Engineering Laboratory conducted a group of column bending experiments under constant axial loading, and the loading paths in the experiments include monotonic loading, diagonal loading, rectangle loading, ellipse loading and circular loading. Six columns, numbering TP074 TP079 were involved in the experiments, in which TP074 and TP075 resists unidirectional loading, and others are under spatial loading.

The cross section of these six columns are squares with a width of $400 \mathrm{~mm}$, the distance between the loading point and the bottom fixed point is $1350 \mathrm{~mm}$. 
The deformation loading paths at the top of columns are shown in Fig.8.

416

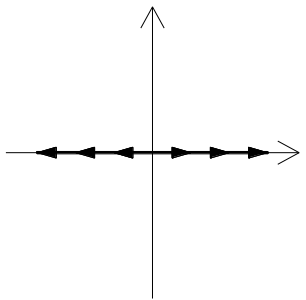

(a)TP074 TP075 monotonic loading

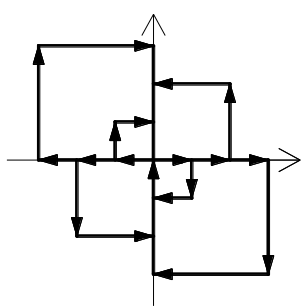

(c)TP077 rectangle loading

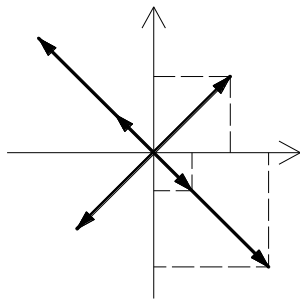

(b)TP076diagonal loading

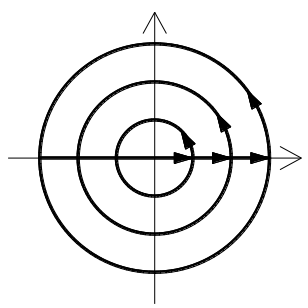

(d)TP078 circular loading

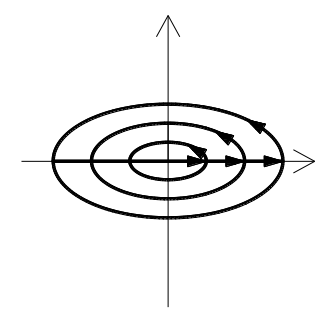

(e)TP079 ellipse loading

Fig.8 Displacement loading paths of Specimens TP074 TP079

Converting the force-deformation of specimen TP074 TP079 relation to

moment-rotation, and calculating the damage value, the results are shown in Fig.9.

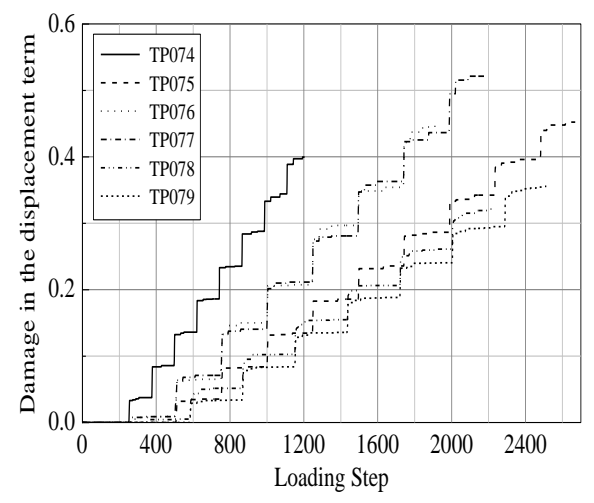

(a)Damage in the displacement term

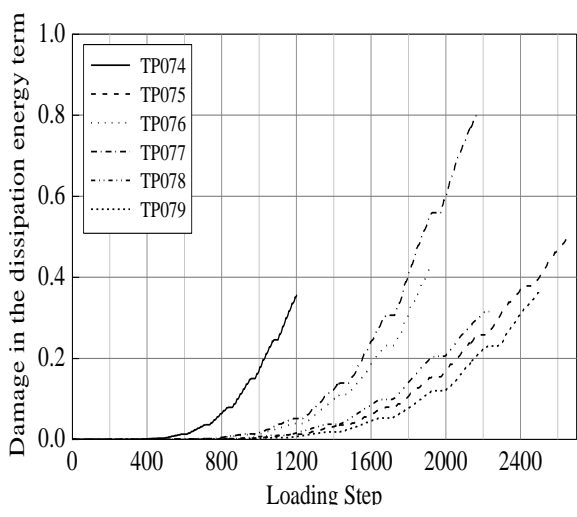

(b)Damage in the dissipation energy term 


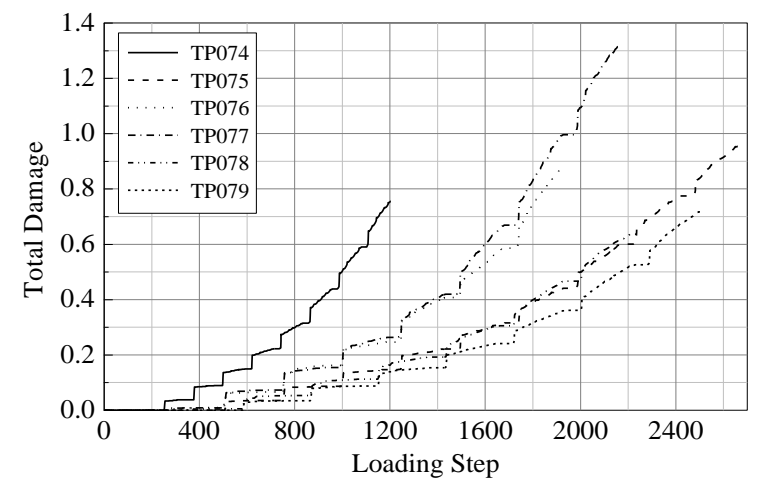

(c)Total damage

According to the performance limit value proposed in this paper, at the end of the final state of all structure members is "collapse" as shown in Table IV.

Table IV Damage state of Specimens TP074 TP079 when loading terminates

\begin{tabular}{ccccccc}
\hline Specimens & TP074 & TP075 & TP076 & TP077 & TP078 & TP079 \\
\hline Displacement damage term & 0.40 & 0.45 & 0.45 & 0.52 & 0.32 & 0.36 \\
Dissipative energy damage term & 0.36 & 0.51 & 0.43 & 0.80 & 0.32 & 0.36 \\
Total Damage value & 0.75 & 0.96 & 0.88 & 1.33 & 0.64 & 0.72 \\
Structural State & Collapse & Collapse & Collapse & Collapse & Should be replaced & Collapse \\
\hline
\end{tabular}

From Table IV, the deviation of damage value is larger than that in unidirectional loading. Due to the large dispersion of the mechanical property of reinforced concrete members, and by the fact that all members except Specimen T078 ended up in collapse just as the model predicted. Since circular loading path of T078 is very regular and with small variability, its capacity of deformation and energy dissipation is much better than other specimens, and its damage value is smaller. Based on the above predicting results, we can still draw a conclusion that the proposed damage model is suitable for spatial loading pattern.

\section{Conclusion}

This paper extended the widely-used Park and Ang damage model to three dimension in 442 terms of moment and rotation. The calculation method of each variable in the extended three 443 dimensional model is introduced in detail. The damage model can deal with cases under 
combined varying axial loading and bi-directional bending. Relevant parameters are determined based on experimental data. And the damage classification is defined.

The conclusions are as follows:

1) The extended Park and Ang model together with the parameters and the performance grading criterion form an integrated damage assessment system. The cases with combined varying axial force and biaxial bending can be considered by the proposed damage model.

2) The applicability of the damage model under various one-dimensional loading paths and under spatial loadings was verified respectively. The proposed model was found to be reliable in evaluating the damage of specimens under various one-dimensional and spatial loading paths.

\section{Acknowledgement}

The study carried out herein is supported by the National Science Foundation of China (Grant Nos. 51508351 and 51438010).

\section{References}

Bozorgnia, Y., Bertero,W. (2001a)."Evaluation of damage potential of recorded earthquake ground motion." Proceedings of The 96th Annual Meeting of Seismological Society of America.

Bozorgnia Y, Bertero VV. (2001b).“Improved shaking and damage parameters for post-earthquake applications." In Proceedings of The SMIP01 Seminar on utilization of strong-motion data. Los Angeles, CA, USA.

Bozorgnia Y, Bertero V V. (2003). "Damage Spectra: Characteristics and Applications to Seismic Risk Reduction.” Journal of Structural Engineering, 129(10):1330-1340.

Banon H, Biggs JM, Irvine HM. (1981)."Seismic damage in reinforced concrete members."Journal of Structural Engineering, 107(9):1713-29. 
Banon H, Veneziano D. (1982)."Seismic safety of reinforced members and structures." Earthquake Engineering and Structural Dynamics, 10(2):179-93.

Banon H, Biggs, JM and Irvine HM, (1980). "Prediction of Seismic Damage in Reinforced Concrete Frames." Seismic Behaviorand Design of Buildings, Report No.3, MIT, Cambridge, Mass.

Colombo A, Negro P. (2005). “A damage index of generalised applicability. ”Engineering Structures, 27(8):1164-74.

Cao, V.,Ronagh, H. (2014). "Reducing the seismic damage of reinforced concrete frames using FRP confinement. " Composite Structures, 118, 403-415.

Chai YH, Romstad KM, Bird SM. (1995). "Energy-Based Linear Damage Model for High-Intensity Seismic Loading.” Journal of Structural Engineering, 121(5): 857-864.

DiPasquale E, Ju J-W, Askar A, Cakmak AS.(1990). "Relation between global damage indices and local stiffness degradation." Journal of Structural Engineering, $116(5): 1440-56$.

Ghobarah A, Abou-Elfath H, Biddah A. (1999).“'Response-based damage assessment of structures.”Earthquake Engineering and Structural Dynamics, 28:79-104.

Gosain N K, Brown R H, Jirsa J O. (1977) Shear requirements for load reversals on RC members, Journal of Structural Engineering, ASCE, Vol. 103, No. 7, 1461-1476.

Kunnath, S.K., Reinhorn, A. M., and Lobo, R. F. (1992).“ IDARC Version 3.0: A Program for the Inelastic Damage Analysis of Reinforced Concrete Structures." Technical Report NCEER-92-0022, National Center for Earthquake Engineering Research, State University of New York, Buffalo NY..

Kim TH, Lee KM, Chung Y-S, Shin HM. (2005).“Seismic damage assessment of reinforced concrete bridge columns.’Engineering Structure, 27:576-92.

Kunnath, Sashi K. \& National Institute of Standards and Technology 
(U.S.).(1997)."Cumulative seismic damage of reinforced concrete bridge piers.”

Gaithersburg, MD :U.S. Dept. of Commerce, Technology Administration, National Institute of Standards and Technology.

Mo, Y. L., Wang, S. J.(2000)."Seismic Behavior of RC Columns with Various Tie Configurations.” Journal of Structural Engineering 126(10), 1122-1130.

Park, Y. J., Ang, AH.S.(1985).“Mechanistic seismic damage model for reinforced concrete.” Journal of Structural Engineering 111(4), 722-739.

Park, Y. J., Ang,AH.S., and Wen, Y. K.(1987). "Damage-Limiting Aseismic Design of Buildings.” Earthquake Spectra 3(1), 1-26.

Powell G.H., Allahabadi R. "Seismic damage prediction by deterministic methods: Concepts and procedures.” Earthquake Engineering \& Structural Dynamics, 1988, 16(5):719-734.

Roufaiel MSL., Meyer C.(1987). “Analytical modelling of hysteretic behaviour of R/C frames.” Journal of Structural Engineering, ASCE, Vol. 113, No. 3, 429-444.

Rodriguez ME, Padilla D.(2009) "A damage index for the seismic analysis of reinforcedconcrete members. ”Journal of Earthquake Engineering ,13(3):364-83.

Stone, W.C., Taylo,r A.W.(1993)."Seismic Performance of circular bridge columns designed in accordance with AASHTO/CALTRANS standards." Gaithersburg MD: National Institute of Standards and Technology.

Takemura, H., Kawashima, K.(1997).“Effect of loading hysteresis on ductility capacity of reinforced concrete bridge pier.’Journal of Structural Engineering 43A, 849-858, Japan.

Wang, D. S., Feng, Q. M., and Wang, G. X.(2004).“A modified Park and Ang seismic damage model considering low-cycle fatigue life.” China Civil Engineering Journal 37(11), 41-49 (in Chinese).

Williams, M. S. , and Sexsmith, R. G. , 1995. "Seismic damage indices for concrete structures: A state-of-the-art review.” Earthquake Spectra 11, 319-349. 
